\title{
BOUNDARY LAYER FLOW AND HEAT TRANSFER WITH VARIABLE VISCOSITY IN THE PRESENCE OF MAGNETIC FIELD.
}

\begin{abstract}
A steady two dimensional boundary layer flow and heat transfer with variable viscosity electrically conducting fluid at $T_{\infty}$ in the presence of magnetic fields and thermal radiation was considered. The governing equations which are partial differential equations were transformed into ordinary differential equations using similarity variables, and the resulting coupled ordinary differential equations were solved using collocation method in MAPLE 18. The velocity and temperature profiles were studied graphically for different physical parameters. The effects of the parameters on velocity and temperature profile were showed.
\end{abstract}

${ }^{1}$ Ajala O.A., ${ }^{2}$ Aseelebe L. O. and ${ }^{3}$ Ogunwobi Z. O

${ }^{1}$ Department of Pure and Applied Mathematics

Ladoke Akintola University of Technology, Ogbomoso, Nigeria.

oaajala@lautech.edu.ng

${ }^{2}$ Department of Pure and Applied Mathematics

Ladoke Akintola University of Technology, Ogbomoso, Nigeria.

aselebekamorudeenoladapo@yahoo.com

${ }^{3}$ Department of Mathematical Sciences,

Olabisi Onabanjo University, Ago-Iwoye, Nigeria.

ogunwobizac@yahoo.com

oaajala@lautech.edu.ng

\section{Keywords: Boundary layer flow; boundary layer thickness; viscosity; magnetic field and heat transfer. INTRODUCTION}

The boundary layer flow and heat transfer in magnetic fields has become industrially more important. The applications arise in space technology, chemical engineering for filtration and purification technology to study the movement of natural gas, oil and water through the oil reservoirs. Also, in Agriculture to study the water transport in plants and trees and so on. If the temperature of the surroundings fluid is rather high, radiation effects play an important role for designing appropriate equipment and this situation does exist in space technology. When radiative heat transfer takes place, the fluid involved can be electrically conducting since it is ionized due to high operating temperature.

Accordingly, examining the effect of magnetic field on the flow becomes more important. The process of fusing of metals in an electrical furnace by applying a magnetic field and the process of cooling of the first wall inside a nuclear reactor containment vessel where the hot plasma is isolated from the wall by applying a magnetic field are some examples of such fields. In controlling momentum and heat transfer in the boundary layer flow of different fluids, applied magnetic field may play an important role.

The interaction of forced convection with thermal radiation has increased greatly during the last decade due to its importance in many practical applications. Radiation heat transfer becomes more important with rising temperature levels and may be totally dominant over conduction and convection at very high temperature. Thus, thermal radiation is important in combustion applications (furnaces, rocket, nozzles, engines, etc.), in nuclear reactors and during atmospheric recently of space vehicles. Many researchers have worked on these, some of them are; Bhattacharyya (2011) analysed the effects of heat source/sink on the steady two dimensional magneto hydrodynamic boundary layer flow and heat transfer past a shrinking sheet with wall mass suction. Makinde (2011) studied the inherent irreversibility in hydro magnetic boundary layer flow of variable viscosity fluid over a semi-infinite flat plate under the influence of thermal radiation and Newtonian heating. Makinde et al. (2012) studied the composite momentum, heat and mass transfer in steady, incompressible laminar boundary layer flow of an electrically conducting fluid past a moving vertical plate with a convective heat exchange at the surface in the presence of a transverse uniform magnetic field and chemically reactive species taking into account first-order and higher-order chemical reactions. Reddy et al (2012) studied MHD boundary layer flow of a non-Newtonian power-law fluid on a moving flat plate. Ghara et al. (2012) studied the effect of radiation on MHD free convection flow past an impulse moving vertical plate with ramped wall temperature. Butt et al. (2014) analyzed Irreversibility effects in magneto hydrodynamic flow over an impulsively started plate. Gururaj and Pavithra (2013) examined Nonlinear hydro magnetic two dimensional steady, laminar, boundary layer flow of a viscous, incompressible, electrically conducting and radiating liquid metal, with nonlinear radiation past a porous plate stretching with power-law velocity is analysed in the presence of a variable magnetic field. Idowu et al (2013) studied heat and mass Transfer of Magneto hydrodynamic (MHD) and Dissipative Fluid Flow Past a Moving Vertical Porous Plate with variable suction.

In this paper, our main focus is on the Boundary Layer Flow and heat transfer with variable viscosity in the presence of Magnetic fields by extending the work of Makinde (2011) to include the effects of space variable.

\section{MATHEMATICAL MODEL}

We considered the steady two-dimensional boundary layer flow and heat transfer with variable viscosity electrically conducting fluid at temperature $T_{\infty}$ in the presence magnetic field and thermal radiation. It was assumed that the lower 
surface of the plate is heated by convection from a hot fluid at temperature $T_{f}$ which provides a heat transfer coefficient $h_{f}$ A uniform transverse magnetic field $B_{0}$ was imposed along the $y$-axis. The induced magnetic field due to the polarization of charges are assumed to be neglected.

Under the usual boundary layer approximations, the flow is governed by the following equations:

$\frac{\partial u}{\partial x}+\frac{\partial v}{\partial y}=\mathbf{0}$

$u \frac{\partial u}{\partial x}+v \frac{\partial v}{\partial y}=\frac{1}{\rho} \frac{\partial}{\partial y}\left(\mu \frac{\partial u}{\partial y}\right)-\frac{\sigma B_{0}^{2}}{\rho}\left(u-U_{\infty}\right)$

$u \frac{\partial T}{\partial x}+v \frac{\partial T}{\partial y}=\alpha \frac{\partial^{2} T}{\partial y^{2}}-\frac{1}{\rho c_{p}} \frac{\partial q_{r}}{\partial y}+\frac{\mu}{\rho c_{p}}\left(\frac{\partial u}{\partial y}\right)^{2}+\frac{\sigma B_{0}^{2}}{\rho c_{p}}\left(u-U_{\infty}\right)^{2}$

where equation (1) is the continuity equation; (2) is the momentum equation; and (3) is the energy equation respectively; with

$U_{\infty}=$ free stream velocity, $c_{p}=$ specific heat at constant pressure, $\alpha=$ thermal diffusivity;

$\sigma=$ fluid electrical conductivity, $\rho=$ fluid density, $\mu$ =dynamic viscosity.

The fluid dynamical viscosity $\mu$ was assumed to be function of space variable $y$.

$$
\mu=\mu_{0} e^{y}
$$

where $\mu_{0}$ is the cold fluid viscosity and $y$ is space variable.

using the Roseland approximation for radiation, the radiative heat flux is simplified as:

$$
q_{r}=-\frac{4 \sigma^{*}}{3 k^{*}} \frac{\partial T^{4}}{\partial y}
$$

$\sigma^{*}$ is the Stephan -Boltzmann constant and $k^{*}$ is the mass absorption coefficient.

The temperature differences within the flow are assumed to be sufficiently small so that $T^{4}$ may be expressed as linear function of temperature $T$ using a truncated Taylor series about the free stream temperature $T_{\infty}$ i.e.

$$
T^{4} \approx 4 T_{\infty}^{3} T-3 T_{\infty}^{4}
$$

The boundary condition at the plate surface and far into the free stream may be written as:

$$
\begin{aligned}
& u(x, 0)=0, v(x, 0)=0,-k \frac{\partial T}{\partial y}(x, 0)=h_{f}\left[T_{f}-T(x, 0)\right] \\
& u(x, \infty)=U_{\infty}, T(x, \infty)=T_{\infty}
\end{aligned}
$$

where, $k$ is the thermal conductivity coefficient.

The stream function $\psi$, satisfies the continuity equation (1) automatically with:

$$
u=\frac{\partial \psi}{\partial y} \text { and } v=-\frac{\partial \psi}{\partial x}
$$

A similarity solution of equations was obtained by defining an independent variable $\eta$ and a dependent variable $f$ in terms of the stream function $\psi$ as:

$$
\eta=y \sqrt{\frac{U_{\infty}}{v x}}, \quad \psi=\sqrt{v x U_{\infty}} f(\eta), v=\frac{\mu}{\rho}, \theta(\eta)=\frac{T-T_{\infty}}{T_{f}-T_{\infty}} .
$$

After introducing equation (9) into Equations (1)-(8), we obtained: 
$e^{y} f^{\prime \prime \prime}+\frac{1}{2} f f^{\prime \prime}+\delta e^{y} f^{\prime \prime}-H a\left(f^{\prime}-1\right)=0$.

$\theta^{\prime \prime}+\frac{1}{2} \beta \operatorname{Pr} f \theta^{\prime}+\beta \operatorname{Bre}^{y}\left(f^{\prime \prime}\right)^{2}+\beta \operatorname{Ha} \cdot \operatorname{Br}\left(f^{\prime}-1\right)^{2}=0$.

$f(0)=0, f^{\prime}(0)=0, f^{\prime}(\infty)=1$,

$\theta^{\prime}(\mathbf{0})=B i[\theta(0)-1], \quad \theta(\infty)=\mathbf{0}$.

Where, $\quad \boldsymbol{\beta}=\frac{\mathbf{3 R a}}{\mathbf{3 R a}+\mathbf{4}}$. and $\boldsymbol{\beta}=1$ corresponds to the absence of thermal radiation influence, where the prime symbol "'" represents the derivative with respect to $\boldsymbol{\eta}$.

where:

$$
\begin{gathered}
\mathrm{Ha}=\frac{\sigma B_{0}^{2} x}{\rho U_{\infty}} \quad \text { (local magnetic field parameter) } \\
\delta \approx \sqrt{\frac{v x}{U_{\infty}} \quad \text { (Boundary layer thickness) }} \\
\operatorname{Ra}=\frac{k k^{*}}{4 \sigma^{*} T_{\infty}^{3}} \quad \text { (Ra is the thermal radiation parameter). } \\
\operatorname{Br}=\frac{\mu_{0} U_{\infty}^{2}}{\boldsymbol{k}\left(\boldsymbol{T}_{f}-\boldsymbol{T}_{\infty}\right)} \quad \text { (The Brinkman number) }
\end{gathered}
$$

\section{Numerical procedure}

This nonlinear differential equation cannot be solved analytically, so recourse must be made to a numerical approach. However no single numerical method is applicable to every nonlinear differential equation. Some of the popular methods that are available to solve these nonlinear differential equations are shooting methods, local similarity and non-similarity methods, collocation method, etc.

These equations under the given boundary conditions were solved numerically by applying collocation method.

We,

- Take $\infty \approx 5$

- Impose boundary condition on a polynomial,

a. Assumed the trial functions as $f=a+b \eta+c \eta^{2}+d \eta^{3}+\ldots$

$$
\theta=a+b \eta+c \eta^{2}+d \eta^{3}+\ldots
$$

and substituting the trial function into the resulting differential equation gives the collocated at various points within the domain.

Residual. The residual was

\section{RESULTS AND DISCUSSION}

The computations were done by a written program which uses a symbolic and computational computer language MAPPLE. The plate surface temperature, the local skin- friction coefficient and the Nusselt number which were respectively proportional to $\theta(0), f^{\prime \prime}(0)$ and $-\theta^{\prime}(0)$, were also worked out and their numerical values were represented in tabular forms. 
Table 1: Computation showing $f^{\prime \prime}(0), \theta(0)$, and $\theta^{\prime}(0)$ for various values of key parameters.

\begin{tabular}{|l|l|l|l|l|l|l|l|l|}
\hline $\mathrm{Bi}$ & $\mathrm{y}$ & $\mathrm{Br}$ & $\mathrm{Ra}$ & $\mathrm{Pr}$ & $\mathrm{Ha}$ & $f^{\prime \prime}(0)$ & $-\theta^{\prime}(0)$ & $\theta(0)$ \\
\hline 0.1 & 0 & 0.1 & 0.7 & 0.72 & 0.1 & 0.3948713134 & 0.06347214374 & 0.3652785626 \\
\hline 1.0 & 0 & 0.1 & 0.7 & 0.72 & 0.1 & 0.46947812315 & 0.1586991113 & 0.8413008887 \\
\hline 0.1 & 0.5 & 0.1 & 0.7 & 0.72 & 0.1 & 0.5309543414 & 0.06197198263 & 0.3802801737 \\
\hline 0.1 & 1.5 & 0.1 & 0.7 & 0.72 & 0.1 & 0.569807966 & 0.05593634397 & 0.4406365603 \\
\hline 0.1 & 0 & 1.0 & 0.7 & 0.72 & 0.1 & 0.6027894290 & 0.02294326748 & 0.9705673252 \\
\hline 0.1 & 0 & 10 & 0.7 & 0.72 & 0.1 & 0.720194572 & 0.5879561961 & 6.8795619615 \\
\hline 0.1 & 0 & 0.1 & 5.0 & 0.72 & 0.1 & 0.3940059928 & 0.06752046764 & 0.3247953236 \\
\hline 0.1 & 0 & 0.1 & 10 & 0.72 & 0.1 & 0.394001777 & 0.06792127703 & 0.3207872297 \\
\hline 0.1 & 0 & 0.1 & 0.7 & 3.0 & 0.1 & 0.382459888 & 0.07517001125 & 0.2482998875 \\
\hline 0.1 & 0 & 0.1 & 0.7 & 7.10 & 0.1 & 0.363547769 & 0.08073780503 & 0.1926219497 \\
\hline 0.1 & 0 & 0.1 & 0.7 & 0.72 & 0.5 & 0.4140059928 & 0.05985400244 & 0.4014599756 \\
\hline 0.1 & 0 & 0.1 & 0.7 & 0.72 & 1.0 & 0.796753026 & 0.0549397485 & 0.4504602515 \\
\hline 0.1 & 0 & 0.1 & 0.7 & 0.72 & 2.0 & 1.04752930 & 0.04515391962 & 0.5484608038 \\
\hline
\end{tabular}

Below is the graphical representation of physical parameter involved on the flow and thermal field

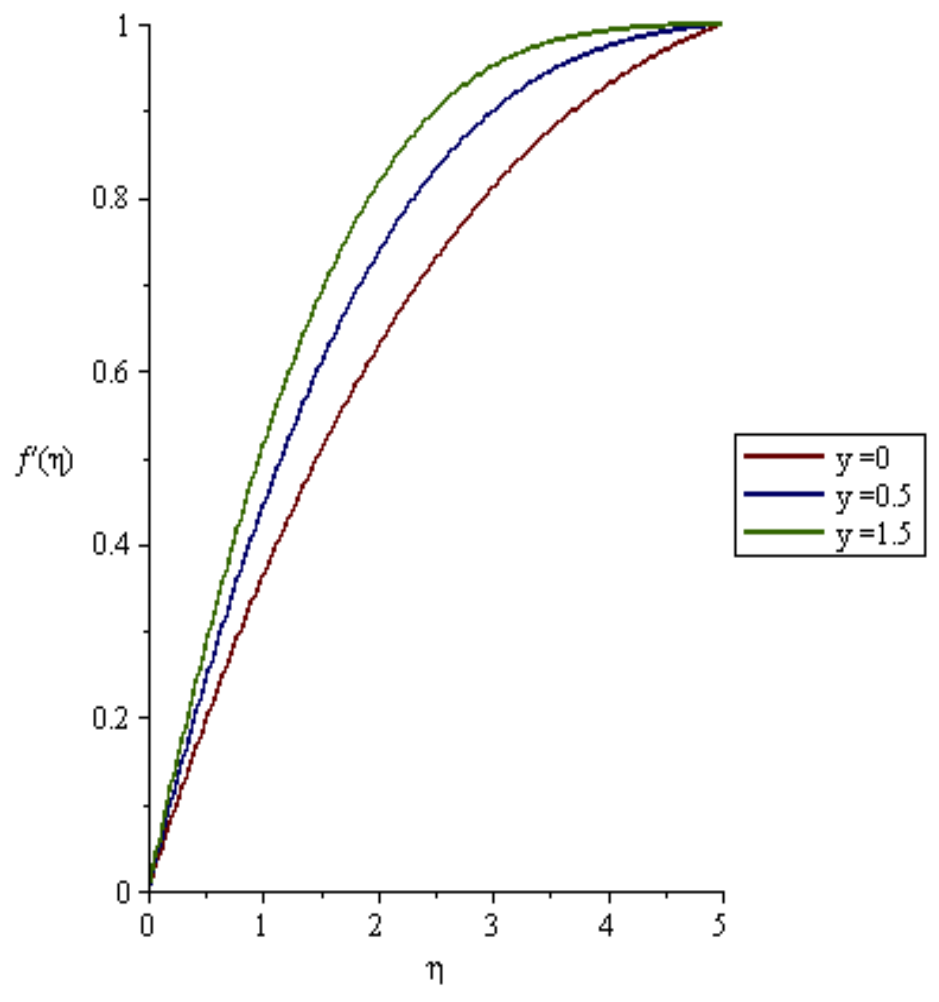

Figure 1: Velocity profile at different values of space variable, $\mathbf{y}$ with $\mathrm{Ha}=0.1, \delta=0.25$. 


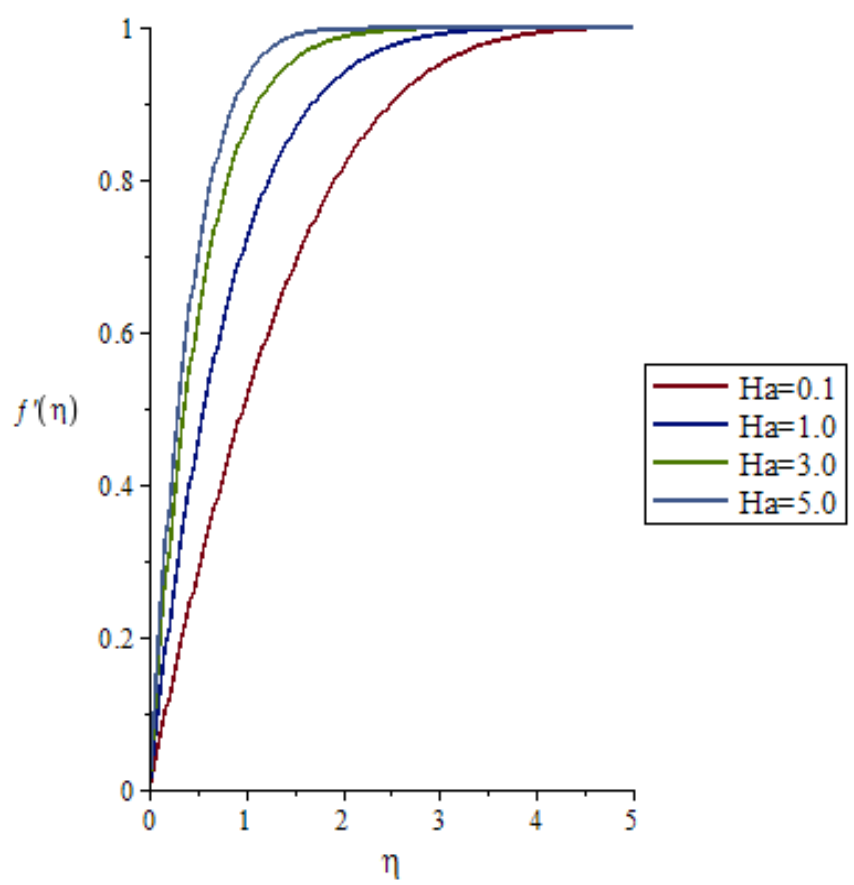

Figure 2: Velocity profile at different values of magnetic field parameter Ha with $y=0, \delta=0.25$

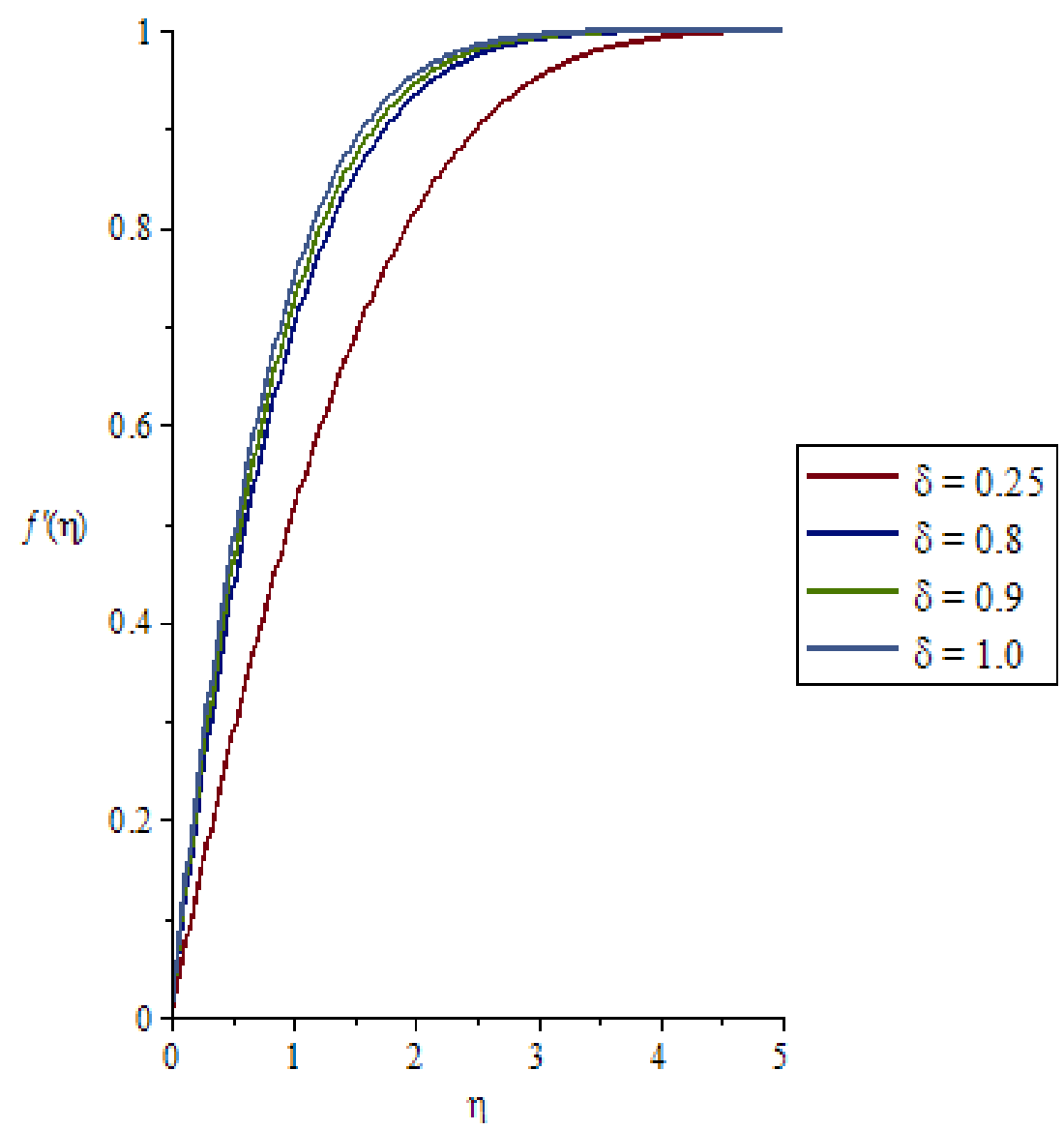

Figure 3: Velocity profile at different values of boundary layer thickness $\delta$ with $y=0, \mathrm{Ha}=0.1$ 


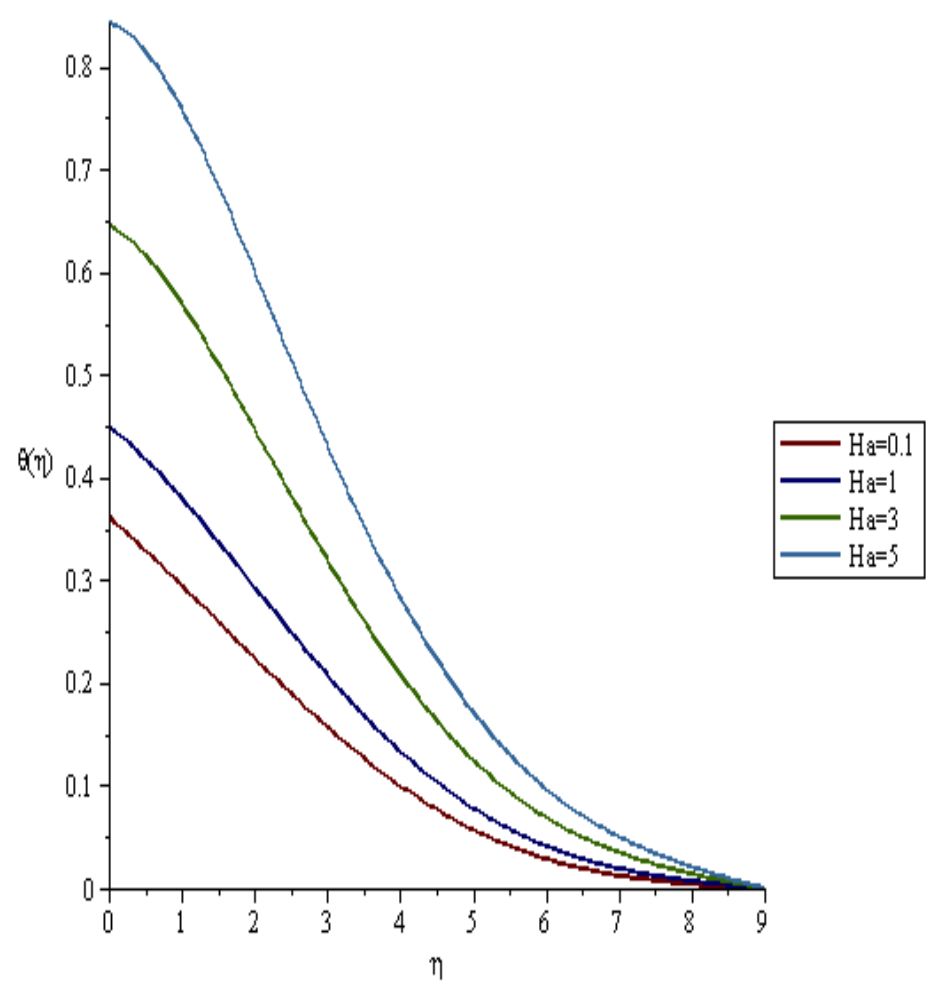

Figure 4: Temperature profile with different values of magnetic field parameter for $\operatorname{Pr}=0.72$,

$\mathrm{Br}=0.1, \mathrm{Ra}=0.7, \mathrm{y}=0, \mathrm{Bi}=0.1$.

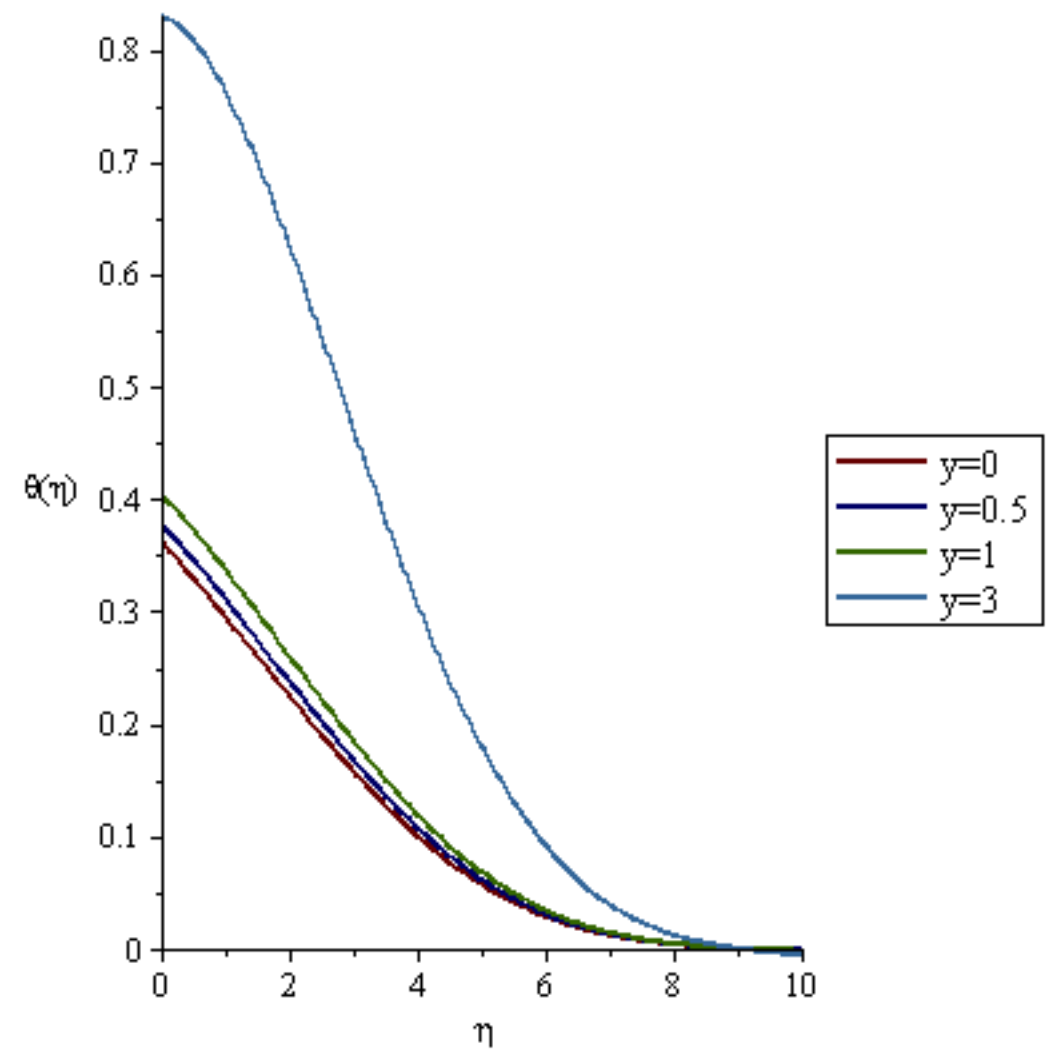

Figure 5: Temperature profile with different values of space variable viscosity for $\operatorname{Pr}=0.72$, 
$\mathrm{Ha}=0.1, \mathrm{Bi}=0.1, \mathrm{Ra}=0.1, \mathrm{Br}=0.1$

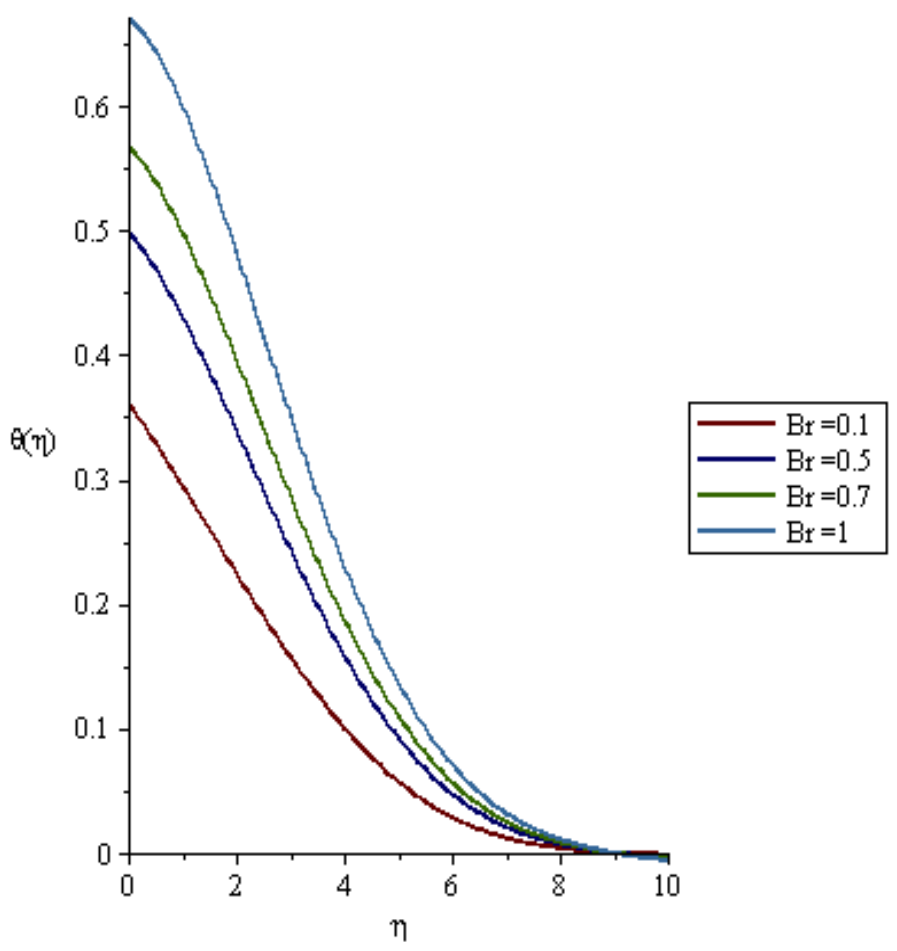

Figure 6: Temperature profile with various values of Brinkmann number for $\operatorname{Pr}=0.72, \mathrm{Bi}=0.1$,

$$
\mathrm{Ra}=0.7, y=0, \mathrm{Ha}=0.1
$$

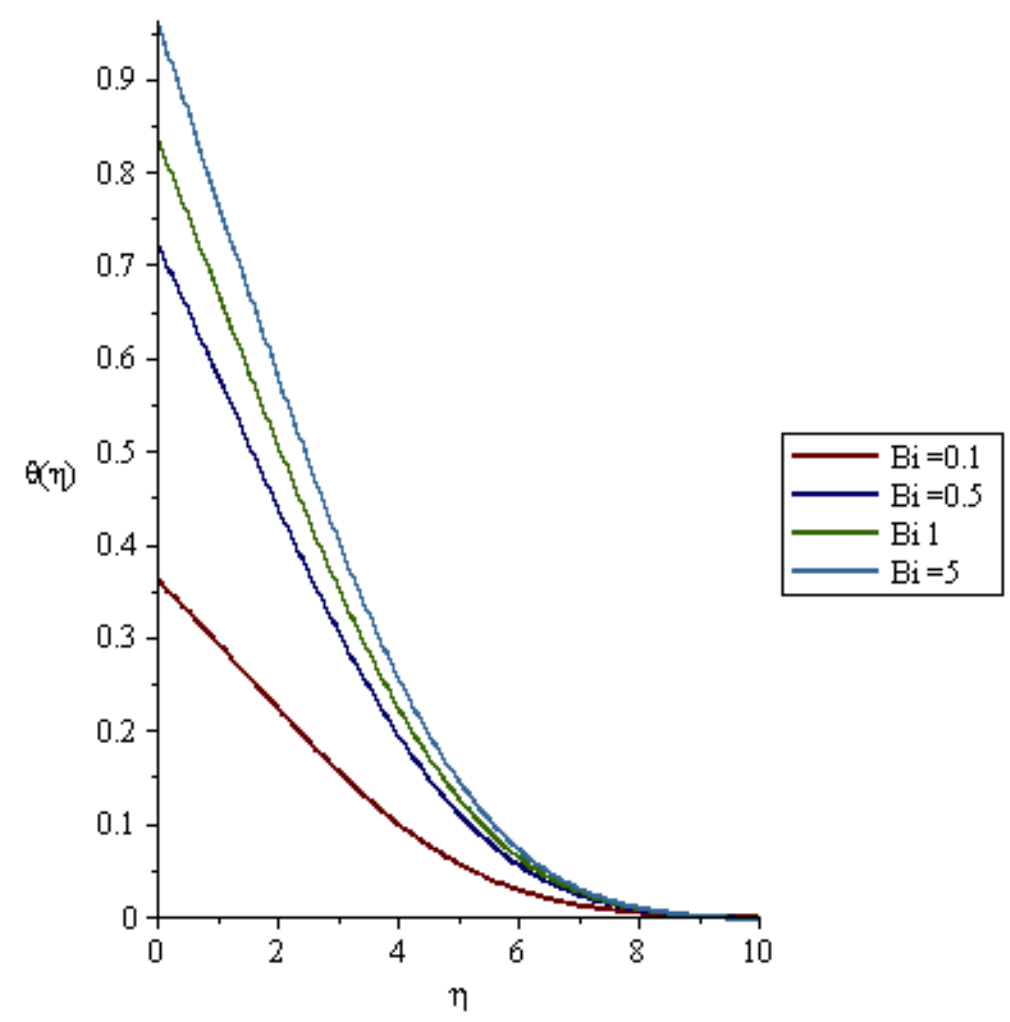

Figure 7: Temperature profiles with different values of Biot number for $\operatorname{Pr}=0.72, \mathrm{Ha}=0.1$,

$$
y=0, \mathrm{Ra}=0.7, \mathrm{Br}=0.1 \text {. }
$$




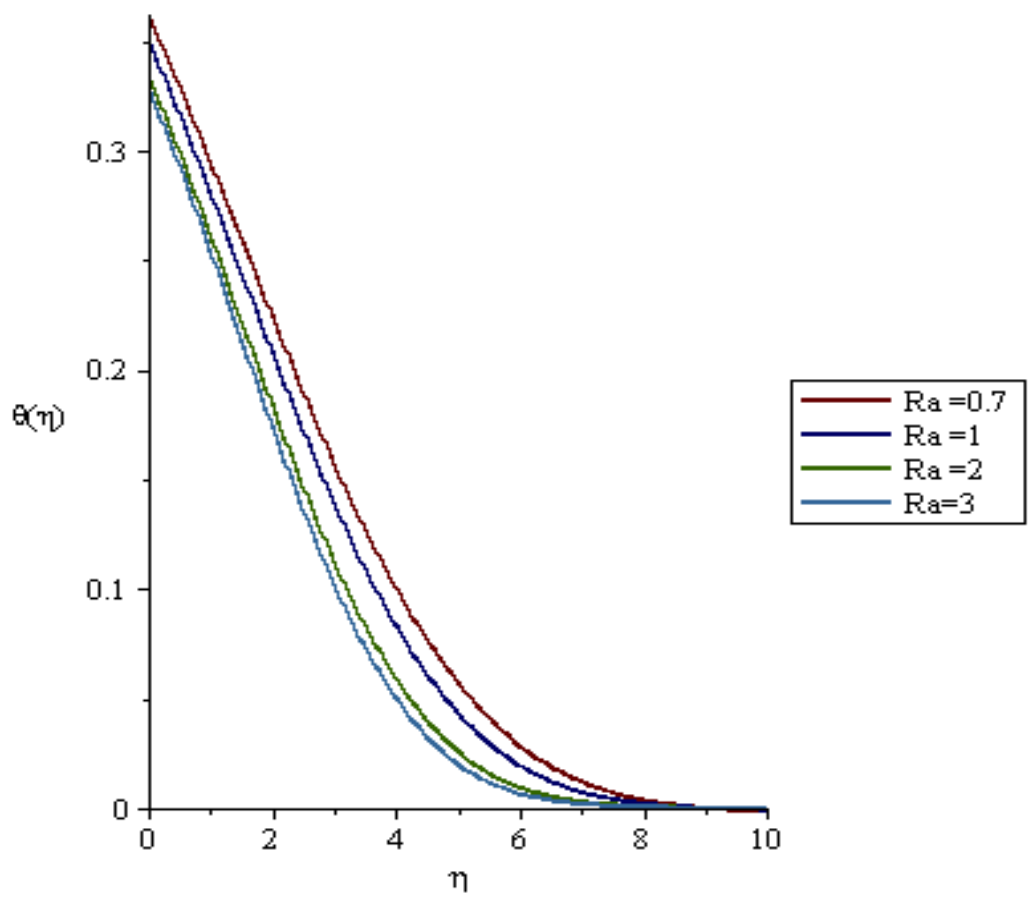

Figure 8: Temperature profiles with different values of Radiation parameters $\operatorname{Ra}$ for $\operatorname{Pr}=0.72$, $\mathrm{Ha}=0.1, \mathrm{Br}=0.1, \mathrm{Bi}=0.1 \mathrm{y}=0$.

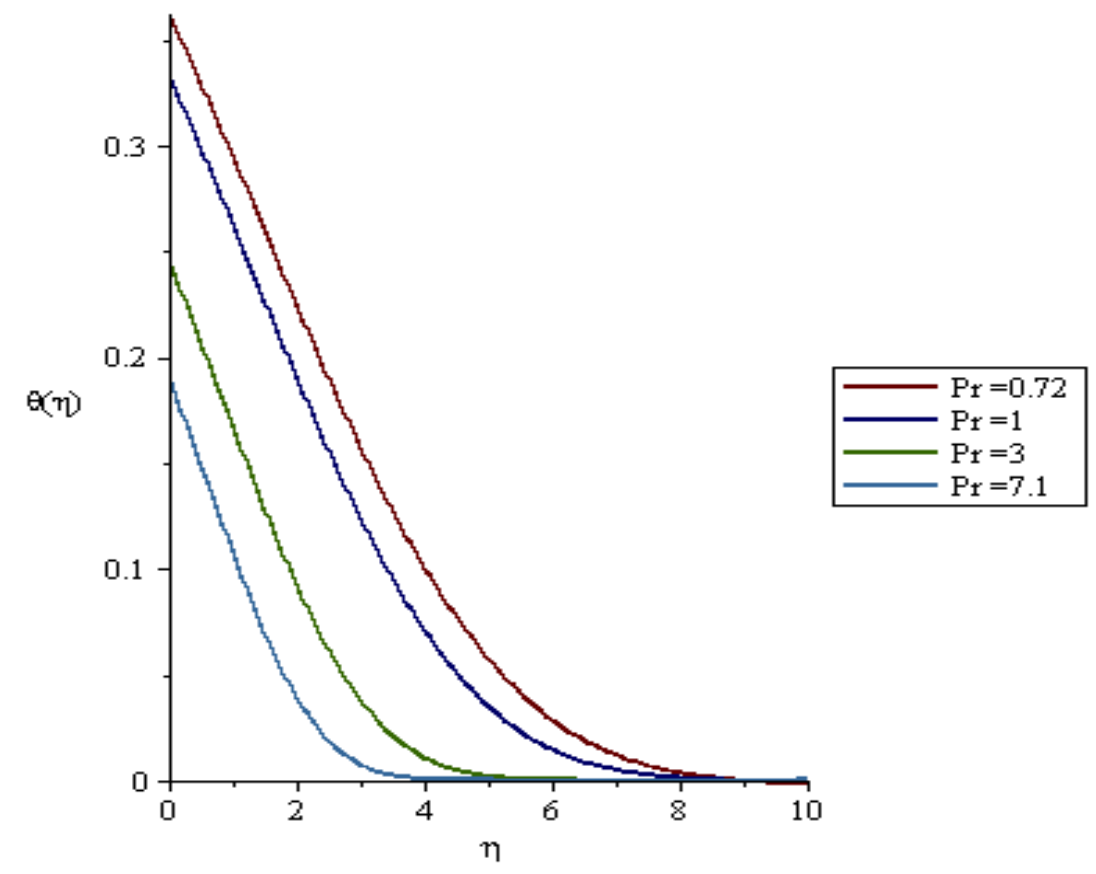

Figure 9: Temperature profile with different values of Prandtl number for $\mathrm{Bi}=0.1, \mathrm{Ha}=0.1$,

$$
\mathrm{Br}=0.1, \mathrm{Ra}=0.7, \mathrm{y}=0 \text {. }
$$

\section{DISCUSSION ON RESULTS}

Figure 1 shows the variation of the velocity profile as a function of $\eta$ at different values of increase in the fluid viscosity (i.e.as parameter $y$ increases), the momentum boundary layer becomes thinner, leading to an increase in the fluid velocity gradient. This is as a result of the increase in the viscosity, which in turn, decreases the velocity.

In figure 2, the fluid velocity is lowest at the plate surface and increases to the free stream value as Ha increases, satisfying the far field boundary condition. Application of the magnetic field creates a resistive force similar to the drag force that acts in the opposite direction of the fluid motion, thus causing the velocity of the fluid to overshoot towards the 


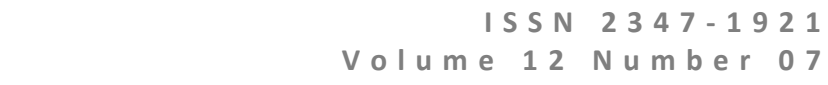

Journal of Advances in Mathematics

plate surface. Similar trend is observed in figure 3 , increase in the velocity profile as the boundary layer thickness increases.

The fluid temperature increases with an increase in $\mathrm{Ha}$ from figure 4 accordingly leading to an increase in thermal boundary layer. The transverse magnetic field gives rise to a resistive force known as the Lorentz force of an electrically conducting fluid. This force makes the fluid experience a resistance by increasing the friction between its layers and thus increases its temperature. It can be seen from the figure 5 that the thermal boundary layer decreases due to a decrease in the fluid viscosity and this causes the temperature of the fluid to decrease.

From figure 6 , it can be observed that as $B r$ increases, thermal boundary layer also increases. This causes the temperature of the fluid to increase. From Figure 7, the thermal boundary layer increases as The $B i$ increases, and this leads to increase in fluid temperature. It is noteworthy from Figure 8 that the fluid temperature decreases with an increase in Radiation parameter $(R a)$ leading to a decrease in the thermal boundary layer thickness. This result qualitatively agrees with the expectations, since the effect of radiation is to decrease the rate of energy transport to the fluid. From figure 9 , the temperature profiles for different values of the Prandtl number decreases with an increase in Prandtl number, consequently the thermal boundary layer decreases.

\section{CONCLUSION}

In the present project, we have theoretically studied the boundary layer flow and heat transfer with variable viscosity in the presence of magnetic field. The partial differential equations were transformed using similarity variables and the resulting non-linear equation were solved using collocation method in MAPLE 18. The velocity and temperature profiles were studied graphically for different physical parameters of space variable, y, Biot number, Bi, Brinkman number, Br, Radiation parameter, Ra, Prandtl number, Pr, and Hartmann number, $\mathrm{Ha}$.

The skin friction, $f^{\prime \prime}(0)$, increases as Biot number, Bi, Brankmann number, $B r$, Space variable, $y$, and Hartmann number, $\mathrm{Ha}$ increase, the skin friction, $f^{\prime \prime}(0)$ decreases with increase in Radiation parameter, Ra, and Prandtl number, Pr. And Nusselt number also increases as Biot number, Bi, Brinkman number, Br, Radiation parameter, Ra, and Prandtl number, $\mathrm{Pr}$, increase, Nusselt number decreases as Space variable, $y$, and Hartmann number decrease. The plate surface temperature $\theta(0)$ increases as Biot number, Bi, Brinkman number, Br, Space variable, $y$ and Hartmann number, $H a$ increase, plate surface temperature $\theta(0)$ decreases as Radiation parameter, Ra, and Prandtl number, Pr, increase

The fluid velocity is lowest at the plate surface and increases to the free stream value as Ha increases, satisfying the far field boundary condition. The velocity profile increases as the boundary layer thickness increases.

\section{REFERENCES}

[1] Abel, M.S, Metri, P.G, Basangouda, V.M. and Narayana, M. (2014): Numerical Study of MHD Boundary Layer Stagnation Point Flow and Heat Transfer over an exponentially stretching surface with Thermal Radiation; IJRET: International Journal of Research in Engineering and Technology, 3(3): Pp.1003-1010.

[2] Ajala, O. A. (2010): PhD Thesis, LAUTECH, Ogbomoso. (Unpublished).

[3] Barik, R.N, (2013): Radiation effect and MHD flow on moving vertical porous plate with Variable temperature; ACTA TECHNICA CORVINIENSIS-Bulleting of Engineering, 3:Pp.45-48.

[4] Bhattacharyya, K. (2011): Effect of heat source/sink on MHD flow and heat transfer over a Shrinking sheet with Suction; Chemical Engineering Research Bulleting, 15: Pp.12-17.

[5] Butt, A.S, Ali, A. and Mehmood, A. (2014): Irreversibility Analysis of Magneto Hydrodynamic Flow over an Impulsively Started Plate; Walailak. J. Science and Technology, 11(11): Pp.923-930.

[6] Ghara, N, Das, S, Maji, S.L, and Jana, R.N. (2012): Effect of radiation on MHD free convection flow past an impulsively moving vertical plate with ramped wall temperature; America Journal of Scientific and Industrial Research,3(6): Pp.376-386.

[7] Gururaj, A.D.M, and Pavithra, C. (2013): Non-linear MHD boundary layer flow of a liquid metal with heat transfer over a porous stretching surface with non-linear radiation effects; Advances in Applied Science Research, 4(2): Pp.77-92.

[8] Idowu, A.S, Dada, M.S, and Jimoh, A. (2013): Heat and mass transfer of MHD and dissipative fluid flow past a moving vertical porous plate with variable suction; Mathematic Theory and Modelling, 3(3): Pp.80-103.

[9] Makinde, O. D, Zimba, K. and Beg O. A. (2012): Numerical Study of Chemically Reacting Hydro magnetic Boundar Layer Flow with Soret/Dufour Effects and a Convective Surface Boundary Condition; Int. J. of Thermal \& Environmental Engineering, 4(1): Pp.89-98.

[10] Makinde, O. D. (2011): Second Law Analysis for Variable Viscosity Hydro magnetic Boundary Layer Flow with Thermal Radiation and Newtonian Heating; Entropy, 13: Pp.1446-1464.

[11] Reddy, B.S, Kishan, N. and Rajasekhar, M.N. (2012): MHD boundary layer flow of anon Newtonian power- law fluid on a moving flat plate; Advances in Applied Science Research, 3(3):Pp.1472-1481. www.aerodynamics-forstudents.html. 